\title{
Optoelectronically mismatched oligophenylethynyl-naphthalenediimide SHJ architectures $\uparrow$
}

\author{
Santanu Maity, ${ }^{a}$ Rajesh Bhosale, ${ }^{a}$ Natalie Banerji, ${ }^{b}$ Eric Vauthey, ${ }^{b}$ Naomi Sakai ${ }^{* a}$ and Stefan Matile ${ }^{* a}$ \\ Received 20th August 2009, Accepted 14th December 2009 \\ First published as an Advance Article on the web 18th January 2010 \\ DOI: 10.1039/b917188f
}

\begin{abstract}
The objective of this study was to evaluate the possibility of photoinduced stack/rod electron transfer in surface "zipper" architectures composed of stacks of blue (B) naphthalenediimides (NDIs) along strings of oligophenylethynyl (OPE) rods. The synthesis and characterization of anionic and cationic multichromophoric OPE-B systems are reported. Absorption spectra suggest that in OPE-B systems, planarity and thus absorption and conductivity of the OPE can possibly be modulated by intramolecular stacking of the surrounding NDIs, although interfering contributions from aggregation remain to be differentiated. Among surface architectures constructed with OPE-B and POP-B systems by zipper and layer-by-layer (LBL) assembly, photocurrents generated by OPE-B zippers exhibit the best critical thickness and fill factors. These findings confirm the existence and functional relevance of topologically matching zipper architectures. In OPE-B zippers, OPEs generate much more photocurrent than the blue NDIs. Ultrafast electron transfer from OPEs to NDIs accounts for these photocurrents, providing wavelength-controlled access to rod-stack charge separation, and thus to formal supramolecular $n / p$-heterojunctions (SHJs). NDI excitation is not followed by the complementary hole transfer to the OPE rod. Scaffolds with higher HOMOs will be needed to integrate blue NDIs into SHJ photosystems.
\end{abstract}

\section{Introduction}

Recently, we have proposed supramolecular $n / p$-heterojunction (SHJ) photosystems with oriented multicolored antiparallel redox gradients (OMARGs) as bioinspired ideal surface architectures. ${ }^{1-3}$ OMARG-SHJs cover a wide range of the solar spectrum to capture as much light as possible, and feature oriented antiparallel redox cascades to make electrons and holes move fast in opposite directions to the electrodes along co-axial molecular electron $\left(\mathrm{e}^{-}\right.$, $n)$ and hole $\left(\mathrm{h}^{+}, p\right)$ transporting channels. Recent breakthroughs to move on from dye-sensitized, bilayer and bulk $n / p$-heterojunction (BHJ) organic solar cells $\mathrm{s}^{4-14}$ towards oriented SHJ architectures ${ }^{1}$ have explored zipper assembly, ${ }^{2,3,15-17}$ ordered layer-by-layer (LBL) assembly, ${ }^{18-23}$ polymer brushes, ${ }^{24}$ electropolymerization, ${ }^{25,26}$ ordered, surface-initiated supramolecular polymerization ${ }^{26,27}$ and covalent capture ${ }^{28}$ as attractive methods. Whereas progress on isolate components such as $\mathrm{SHJs},{ }^{29-31}$ redox cascades and rainbow systems $^{32-45}$ has been made recently, OMARG-SHJs remain far beyond reach. ${ }^{1}$ To tackle this central challenge in molecular optoelectronics, we have introduced a zipper assembly. ${ }^{15-17}$ Original "zipper" architectures such as Au-1-(2-3- $)_{n}$ are composed of e-transporting stacks of naphthalenediimides (NDIs) along $\mathrm{h}^{+}$transporting strings of $p$-oligophenyl (POP) rods (Fig. 1). NDIs appear ideal for the development of OMARG-SHJ zipper

${ }^{a}$ Department of Organic, University of Geneva, Geneva, Switzerland. E-mail: stefan.matile@unige.ch; Fax: +41 22379 5123; Tel: +41 22379 6523; Web: www.unige.ch/sciences/chiorg/matile/

${ }^{b}$ Department of Physical Chemistry, University of Geneva, Geneva, Switzerland

$\dagger$ Electronic supplementary information (ESI) available: Materials and methods, synthesis, conformational studies, and photocurrent generation. See DOI: $10.1039 / \mathrm{b} 917188 \mathrm{f}$ architectures because they unify decreasing $\mathrm{HOMO} / \mathrm{LUMO}$ levels with increasing HOMO/LUMO gaps, ${ }^{32-37}$ coverage of the full visible range, $n$-semiconductivity, ${ }^{46,47} \pi$-acidity ${ }^{48}$ planarity, global structural preservation, compactness ("atom efficiency") and synthetic accessibility. ${ }^{1-3}$ As a proof of concept, we have constructed zipper assemblies with redox gradients in the $\mathrm{e}^{-}$-transporting channels using different NDIs and shown that the gradients indeed matter for function. ${ }^{16}$ To also install redox gradients in the $\mathrm{h}^{+}$-transporting pathways, the original POPs have been complemented with oligophenylethynyls (OPEs) as $\mathrm{h}^{+}$-transporting rigid-rod scaffolds. ${ }^{2}$ OPEs do not only have a higher HOMO, they also excel with topologically matching repeat distances for $\pi$-stacks $(\sim 7 \AA)$, planarizability ${ }^{49-51}$ high conductivity ${ }^{52-54}$ and absorption of visible light. Different to red $\left(\mathrm{R}_{\mathrm{Cl}}\right)^{17}$ and yellow NDIs (Y), ${ }^{3}$ POP zippers with blue NDIs (B) are incompatible with SHJs. ${ }^{15,16}$ Excitation of blue NDI is not followed by hole transfer to neighboring POPs because their HOMO is too low. ${ }^{36,37}$ As a result, photoinduced rod/stack charge separation to place electrons in the $\mathrm{e}^{-}$-transporting NDI stacks and holes in the $\mathrm{h}^{+}$transporting POP rods is not possible. The consequence of this optoelectronic mismatch is that blue NDIs generate very little photocurrent and cannot be integrated into future OMARGSHJs. ${ }^{1,15-18}$ The high HOMO of OPEs suggested that they could accept holes, not only from POP, but also from blue NDIs. To address this question, here we report the synthesis and evaluation of multichromophoric OPE-B systems. We find that, although OPEs cannot accept holes from blue NDIs, OPE-B systems can form SHJ photosystems by electron transfer after OPE rather than NDI excitation. Moreover, we report that the conformation of OPEs can possibly be controlled by intramolecular NDI stacking and confirm the importance of topological matching ${ }^{2}$ to build ordered SHJ architectures on solid grounds. 


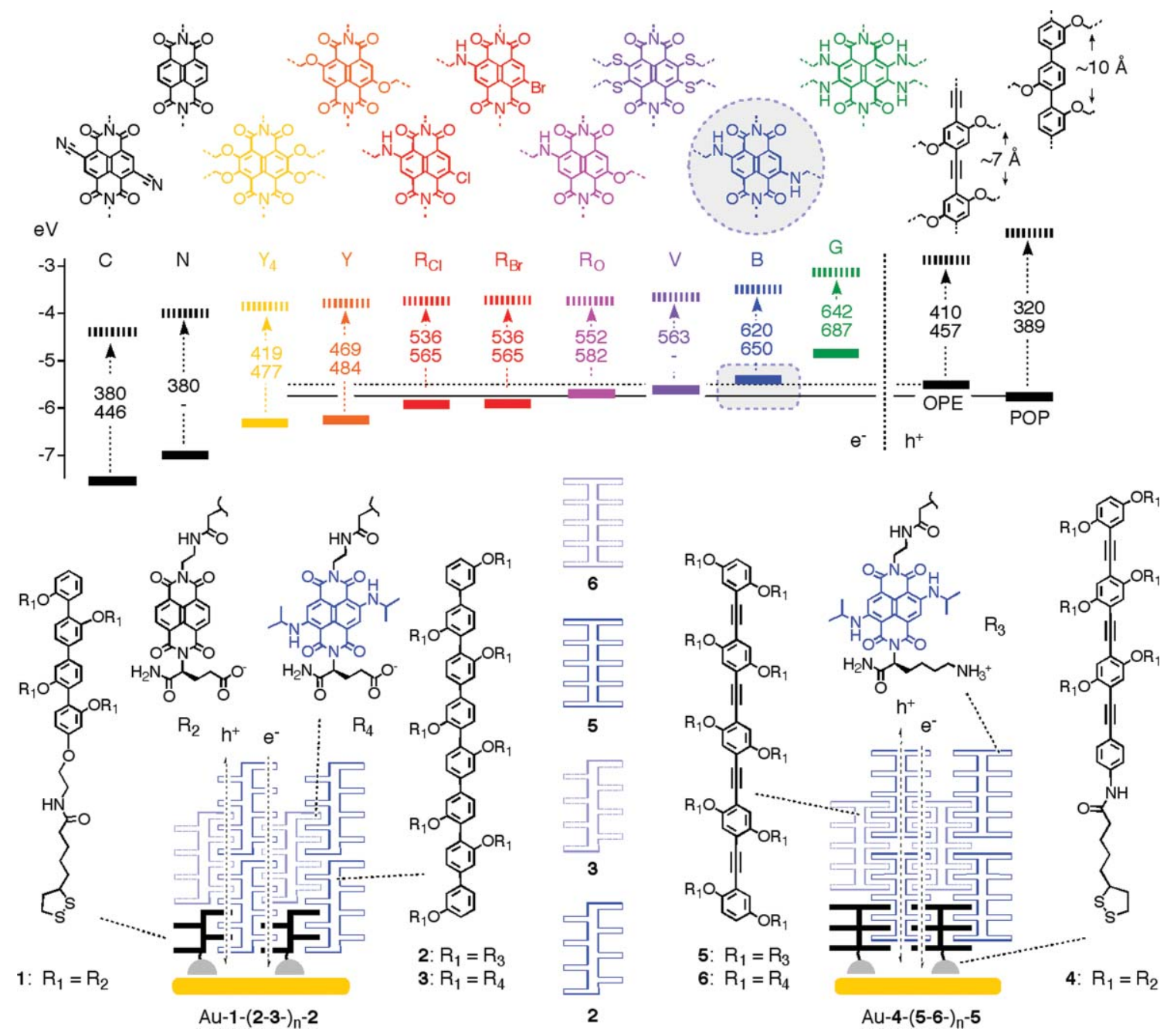

Fig. 1 Energetics of NDIs (general structures $\mathrm{C}-\mathrm{G}$ ), OPEs and POPs (solid lines, HOMO; dashed lines, LUMO; dashed arrows, absorption of light $(h v)$ with wavelength (nm) of maximal absorption (top) and emission (bottom)), structure of POP-N and OPE-N initiators and POP-B and OPE-B propagators, and notional zipper architectures with possible oriented (single arrow) or disoriented (double arrow) $\mathrm{h}^{+}$- and $\mathrm{e}^{-}$-transporting pathways.

\section{Results and discussion}

\section{Synthesis}

OPE 7 was prepared from arene $\mathbf{8}$, acetylene $\mathbf{9}$ and acetate $\mathbf{1 0}$ by repeated Sonogashira couplings following recently developed procedures (Scheme 1). ${ }^{2}$ Reaction of the ten acids along the scaffold of pure OPE 7 with the amine at one end of blue NDIs $\mathbf{1 1}$ in the presence of a carefully optimized cocktail of coupling reagents (HATU) and bases (di-tBu-pyridine, TEA) in freshly distilled DMF gave OPE-B 12. Deprotection of the amines with thioanisole, pentamethylbenzene and trifluoroacetic acid (TFA) gave the cationic propagator 5. The anionic propagator 6 was prepared analogously by reaction of OPE 7 with NDI 13 and deprotection of OPE-B 14.

\section{Conformational studies}

The absorption spectrum of the anionic OPE-B propagator 6 in trifluoroethanol (TFE) containing $10 \%$ water was dominated by NDI absorptions at $620 \mathrm{~nm}$ and $370 \mathrm{~nm}$ (Fig. 2A, blue). The
OPE absorption was essentially absent, visible only as a very weak shoulder around $380 \mathrm{~nm}$. This observation was in sharp contrast to the very well visible OPE maximum above $400 \mathrm{~nm}$ with the corresponding OPE- $\mathrm{R}_{\mathrm{Br}}$ and came as a surprise. ${ }^{2}$ However, spectroscopic and analytical data unambiguously confirmed identity and homogeneity of OPE-B propagator 6.

Increasing solvent polarity caused a gradual decrease of the NDI absorptions. The NDI hypochromism coincided with a redshift of the OPE band from $380 \mathrm{~nm}$ to $405 \mathrm{~nm}$. In water containing $10 \%$ TFE, the OPE maximum at $405 \mathrm{~nm}$ was clearly separated from the high-energy NDI band (Fig. 2A, red, bold). In pure water, OPE bathochromism and NDI hypochromism intensified but could be more affected by the onset of significant aggregation and ultimately precipitation (Fig. 2A, dotted, red).

Under optimized conditions in water containing $10 \% \mathrm{TFE}$, the absorption spectrum of OPE-B 6 showed surprisingly little $\mathrm{pH}$ dependence (Fig. 2B). A relatively minor NDI hyperchromism in response to charge removal at high $\mathrm{pH}$ was not accompanied by the corresponding OPE hypsochromism.

OPE can exist with adjacent arenes oriented co-planar or twisted to each other. ${ }^{49-51}$ Due to the very small energy differences, 


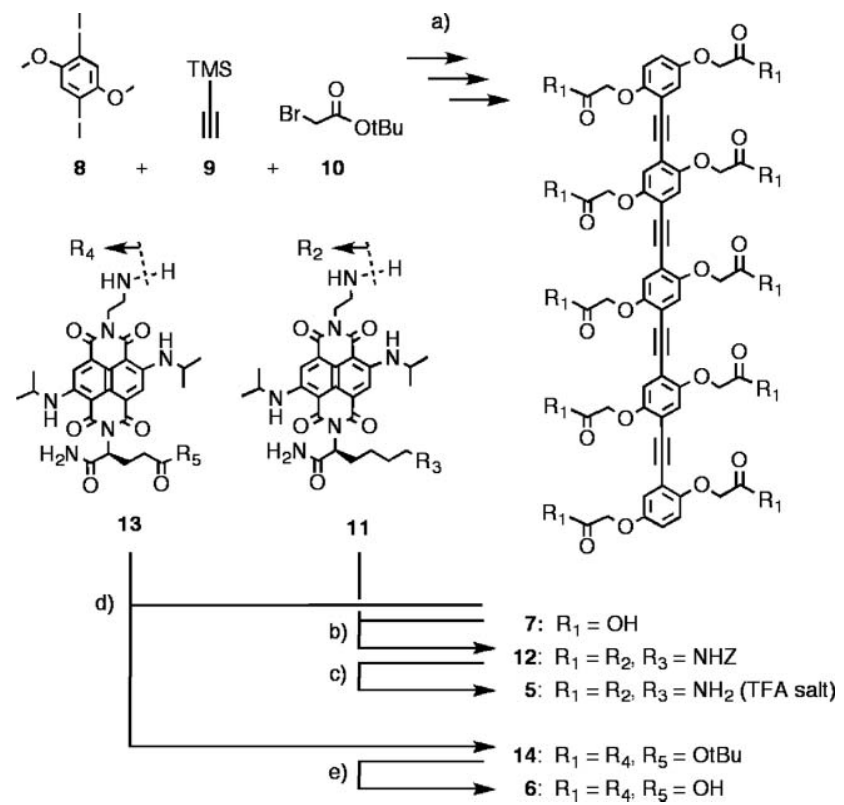

Scheme 1 (a) Several steps, as in ref. 2. (b) HATU, di-tBu-pyridine, TEA, DMF $(25 \%)(Z=$ benzyloxycarbonyl). (c) Thioanisole, pentamethylbenzene, TFA (quant). (d) HATU, di-tBu-pyridine, TEA, DMF (35\%). (e) TFA, $\mathrm{CH}_{2} \mathrm{Cl}_{2}$ (quant).

these conformers usually co-exist in solution at room temperature. In planar conformation, the two arenes next to a triple bond are conjugated, whereas OPE deplanarization interrupts conjugation at the triple bond. Increasing conjugation by OPE planarization causes a red-shift of the OPE band. The coincidence of OPE bathochromism and NDI hypochromism found with multichromophoric OPE-B system 6 indicated that intramolecular NDI stacking could cause OPE planarization. Sensitivity toward solvent polarity rather than $\mathrm{pH}$ suggested that OPE planarization by NDI stacking is more effective than OPE deplanarization by charge repulsion. This interpretation was in agreement with the much stronger OPE bathochromism observed with more $\pi$-acidic NDIs. ${ }^{2}$ Because conductivity, photoinduced charge separation and charge recombination could vary with OPE planarity, the found conformational control by reversible sidechain interactions is attractive for potential applications towards optoelectronic switches. Although OPE aggregation is not expected to cause similar red-shifts, contributions from this and other effects are undissectible and can not be vigorously excluded at this point. The interpretation of OPE bathochromism as sidechain-induced planarization has thus been considered with appropriate caution.

\section{Photoinduced charge separation (PCS) and charge recombination (CR)}

According to transient absorption spectroscopy, excitation of the blue NDIs in monomeric OPE-B $\mathbf{5}$ is followed by PCS between adjacent NDIs. ${ }^{55}$ In sharp contrast, OPE excitation at $400 \mathrm{~nm}$ is followed by ultrafast electron (rather than energy) transfer in the femtosecond time-scale from the OPE to the NDI. This demonstrated that the relatively long-lived $(\mid \sim 5 \mathrm{~ns})$, SHJ-compatible $\mathrm{OPE}^{+\cdot-\mathrm{NDI}^{-}}$pair is accessible only by OPE excitation, whereas NDI excitation gives the SHJ-incompatible $\mathrm{NDI}^{+}-\mathrm{NDI}^{-}$pair. This excitation-wavelength dependence of
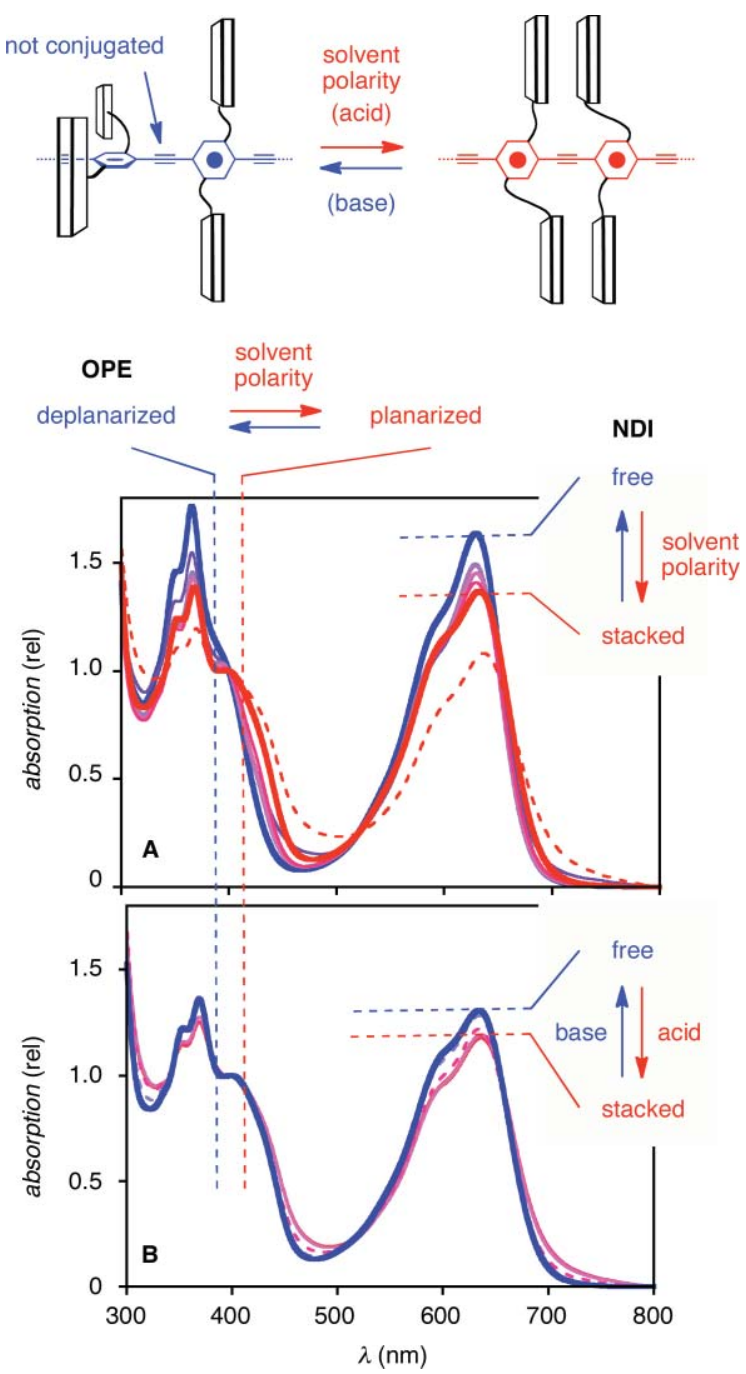

Fig. 2 Absorption spectra of anionic OPE-B 6 as a function of (A) solvent polarity and (B) $\mathrm{pH}$. (A) Spectra in TFE containing 10\% (blue), 30\%, 50\%, $60 \%, 70 \%$, and $90 \%$ (red) $\mathrm{H}_{2} \mathrm{O}$, and in $\mathrm{H}_{2} \mathrm{O}$ (red, dashed). (B) Spectra in $\mathrm{H}_{2} \mathrm{O}-\mathrm{TFE} 9$ : 1 at $\mathrm{pH} 3$ (red), $\mathrm{pH} 4, \mathrm{pH} 5, \mathrm{pH} 6, \mathrm{pH} 7$ (dashed), $\mathrm{pH} 8, \mathrm{pH} 9$ and $\mathrm{pH} 10$ (blue).

CS pathways is of interest in ultrafast photophysics and will be described elsewhere in detail..$^{55}$

\section{Zipper and LBL assembly}

Zipper assembly of formal SHJ architectures such as Au-4(5-6-) $)_{n}$ begins with the anionic OPE-N initiator 4 (Fig. 3A). The disulfide at one end is expected to bind covalently to gold surfaces; the NDI acceptors along the short OPE scaffold are charged negatively to avoid non-specific interaction with gold. A formal Au-4 monolayer was prepared following previously reported procedures. ${ }^{15}$ Decreasing ability of the coated electrode to mediate the reduction of ferricyanate indicated the increasing surface coverage with increasing incubation time of gold electrodes in the solution of initiator 4. Complete and ordered surface coverage was confirmed by atomic force microscopy (AFM). ${ }^{2}$

Formal Au-4 monolayers were immersed into solutions of cationic OPE-B propagators 5. Driven by $\pi, \pi$-stacking, and supported and directed by intrastack hydrogen bonding and 
A
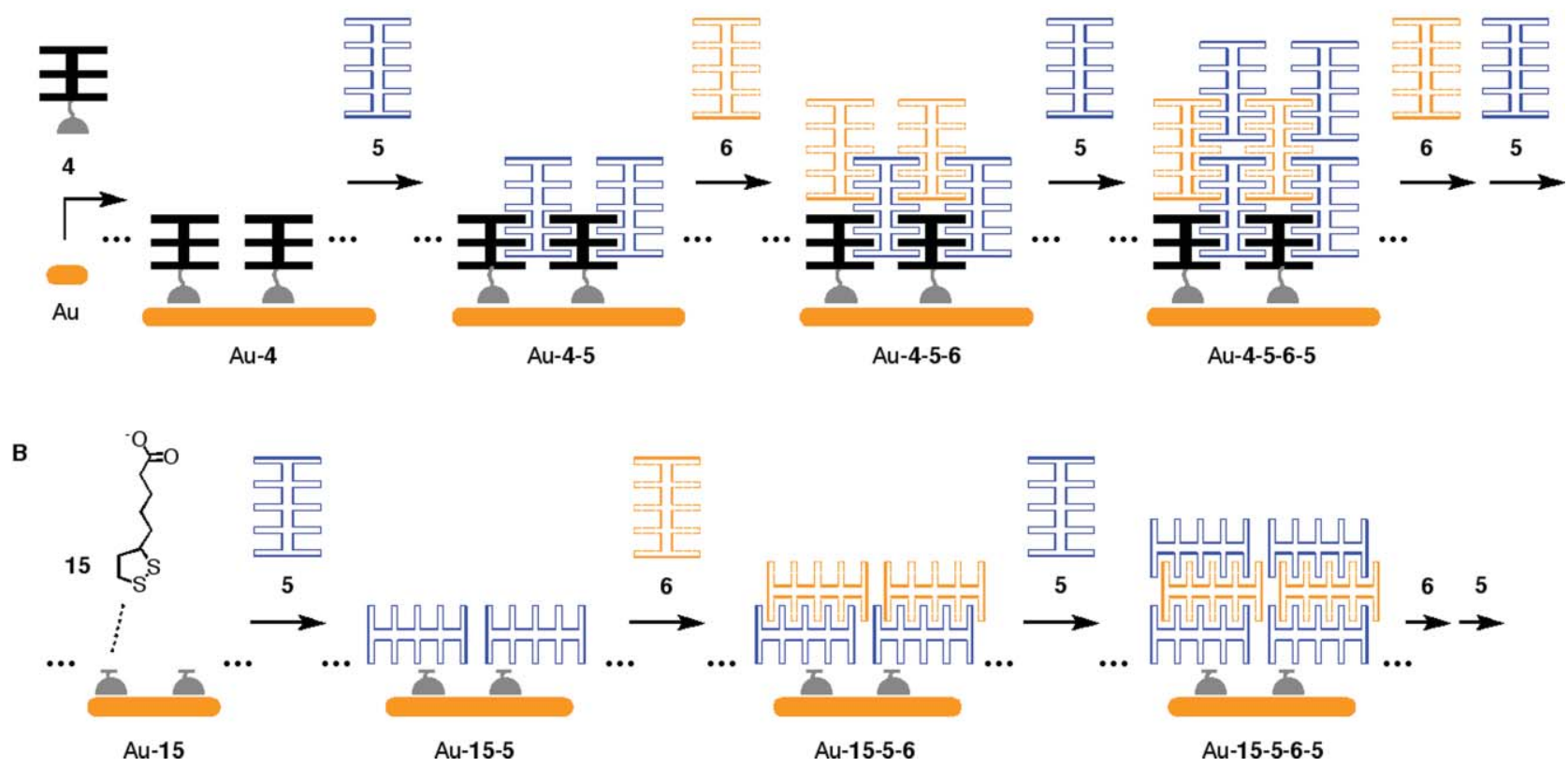

Fig. 3 Zipper (A) and LBL assembly (B) of OPE-B systems from 5 and 6 on gold initiated by OPE-N 4 and lipoic acid 15, respectively. All suprastructures are speculative representations drawn with the only intention to illustrate the concepts.

interstack ion pairing, ${ }^{15}$ the lower half of the blue and cationic NDIs of $\mathbf{5}$ is thought to $\pi$-stack with the anionic NDIs of initiator 4, whereas the upper half remains free as a "sticky end" to zip up with the complementary anionic OPE-B propagator $\mathbf{6}$. The formation of Au-4-5 bilayers was followed by the increasing ability to generate photocurrents and continued until saturation was reached. The resulting Au-4-5 bilayer was dipped into a solution of the anionic OPE-B propagator 6, the resulting Au-4-5-6 into solution of propagator $\mathbf{5}$, and so on, to produce the series of OPE zippers Au-4-(5-6-) .

To compare zipper assembly with the presumably less ordered and certainly not oriented LBL assembly, the same procedure was repeated with lipoic acid $\mathbf{1 5}$ in place of the initiator $\mathbf{4}$ (Fig. 3B). ${ }^{2,3}$ The anionic surface of formal Au-15 monolayers was likely to non-specifically attract cationic OPE-B 5, the resulting Au-15-5 bilayers anionic OPE-B 6, and so on to give the complementary series of LBL photosystems Au-15-(5-6- $)_{n}$, respectively. Previous systematic comparisons have shown that disfunctional zippers give the same response (photocurrent, etc.) as the corresponding LBL systems, whereas functional zippers are clearly superior. ${ }^{2}$

\section{$J-L$ profiles}

The photocurrent density vs. number of layers $(J-L)$-profile of OPE zippers Au-4-(5-6-) $)_{n}$ was characterized by critical thickness, $L_{\mathrm{c}}=13$ layers and maximal photocurrent density, $J_{\max }=$ $4.2 \mu \mathrm{A} \mathrm{cm}^{-2}$ (Fig. 4, - ; Table 1, entry 1). LBL assembly of OPE-B systems Au-15-(5-6-) $)_{n}$ gave $L_{\mathrm{c}}=6$ layers and $J_{\max }=2.0 \mu \mathrm{A} \mathrm{cm}{ }^{-2}$ (Fig. 4, $\bigcirc$; Table 1, entry 2). Prepared under comparable conditions, both critical thickness and maximal photocurrent density obtained with OPE zippers exceeded those of POP zippers Au-1$(\mathbf{2 - 3}-)_{n}$ on the one hand ${ }^{3}$ and LBL architectures Au-15-(5-6- $)_{n}$ on the other (Table 1, entry 1 vs. 2 and 3). This finding completed a consistent set of evidence in support of the existence of zipper

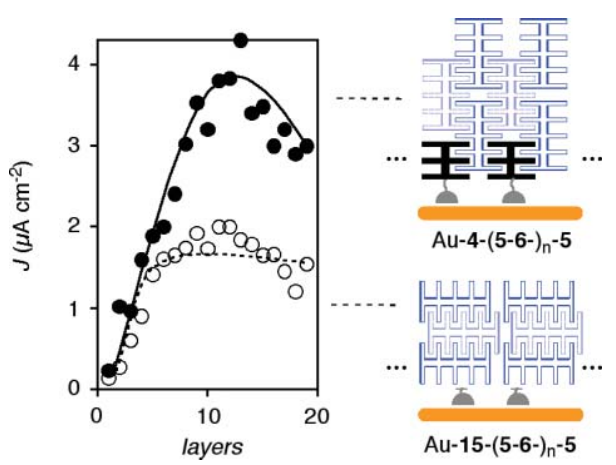

Fig. 4 Current-layer $(J-L)$ profiles of OPE-B architectures obtained by zipper assembly Au-4-(5-6-) $)_{n}(\bullet)$ and LBL assembly Au-14-(5-6-) $)_{n}(\bigcirc)$, lines are added to guide the eye.

architectures and confirmed previous results ${ }^{2}$ on the importance of topological matching with OPE scaffolds.

\section{$J-V$ profiles}

The photocurrent generated by POP zippers Au-1-(2-3- $)_{4}$ under optimized conditions depended almost linearly on the applied voltage (Fig. 5, O). The fill factor, a measure for the maximal power generated with light, ${ }^{1}$ was calculated to a very modest $\mathrm{FF}=$ 0.34 (Table 1, entry 3). Compared to the POP zipper, both OPE systems Au-4-(5-6-) $)_{4}-5$ and Au-15-(5-6- $)_{4}-5$ showed much less linear $J-V$ behavior (Fig. 5, $\bullet, \square$ ). As a result, they had much higher FF $\sim 0.55$ (Table 1, entries 1 and 2). The short circuit current generated by the OPE zipper Au-4-(5-6- $)_{4}-5$ was almost double of that of LBL assembly Au-15-(5-6-) $)_{4}-5$. These $J-V$ characteristics can be interpreted as corroborative support for superior organization with OPE compared to POP scaffolds in general and zipper architectures in particular. However, the 
Table 1 Characteristics of OPE and POP zipper and LBL photosystems ${ }^{a}$

\begin{tabular}{|c|c|c|c|c|c|c|c|}
\hline Entry & Architecture $^{b}$ & Designation $^{b}$ & $L_{\mathrm{c}}$ (layers) $^{c}$ & $J_{\max } / \mu \mathrm{A} \mathrm{cm}^{-2 d}$ & $J_{\mathrm{SC}} / \mu \mathrm{A} \mathrm{cm}-2 e, f$ & $V_{\mathrm{OC}} / \mathrm{V}^{e, g}$ & $\mathrm{FF}^{e, h}$ \\
\hline 1 & $\mathrm{Au}-4-(5-6-)_{n}-5$ & OPE zipper & 13 & 4.2 & 6.5 & -0.56 & 0.52 \\
\hline 2 & $\mathrm{Au}-15-(5-6-)_{n}-5$ & OPE LBL & 6 & 2.0 & 3.8 & -0.53 & 0.56 \\
\hline $3^{i}$ & Au-1-(2-3-) -2 & POP zipper & 8 & 0.8 & 2.8 & -0.33 & 0.34 \\
\hline $4^{i}$ & $\mathrm{Au}-15-(2-3-)_{n}-2$ & POP LBL & - & $<0.3$ & - & - & - \\
\hline
\end{tabular}

${ }^{a} J-V$ data are given for $n=4 .{ }^{b}$ See Fig. 2 and 3, and text for details. ${ }^{c}$ Critical thickness in $J-L$ curves, from Fig. 4. ${ }^{d}$ Maximal photocurrent density in $J-L$ curves, from Fig. 4 (measured at low input power $P_{\text {in }}=66 \mathrm{~mW} \mathrm{~cm}^{2}$ ). ${ }^{e} J-V$ data, from Fig. 6 (measured at high input power $P_{\text {in }}=87 \mathrm{~mW} \mathrm{~cm}{ }^{2}$ ). ${ }^{f}$ Short circuit current density. ${ }^{g}$ Open circuit voltage. ${ }^{h}$ Fill factor $\mathrm{FF}=$ maximum power $/\left(V_{\mathrm{OC}} \times J_{\mathrm{SC}}\right)=\left(V_{\mathrm{m}} \times J_{\mathrm{m}}\right) /\left(V_{\mathrm{OC}} \times J_{\mathrm{SC}}\right), V_{\mathrm{m}}=$ voltage at maximal power $P_{\max }, J_{\mathrm{m}}=$ photocurrent density at $P_{\max }$. Photocurrents in $J-V$ profiles are higher than in $J-L$ profiles (Fig. 4 and 5) because they were measured at higher irradiation power. ${ }^{i}$ Data from ref. 3.

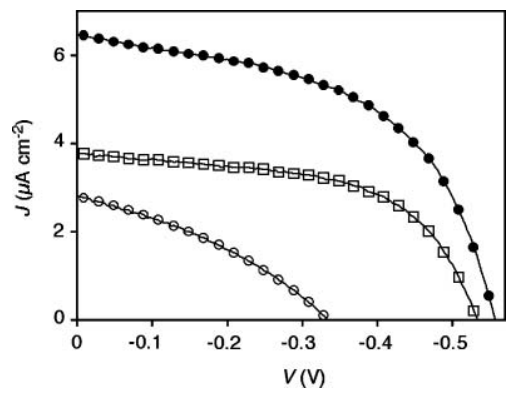

Fig. 5 Current-voltage $(J-V)$ profile of POP-B zipper Au-1-(2-3- $)_{4}(\bigcirc)$, OPE-B zipper Au-4-(5-6-) $)_{4}-5$ (๑) and OPE-B LBL Au-15-(5-6-) 4 -5 ( $\square$ ), see Table 1 for short circuit current densities $\left(J_{\mathrm{SC}}\right)$, open circuit voltages $\left(V_{\mathrm{OC}}\right)$, and fill factors $(F F)$. Photocurrents in $J-V$ profiles are higher than in $J-L$ profiles (Fig. 4) because they were measured at higher irradiation power.

$J-V$ characteristics of POP zippers Au-1-(2-3- $)_{4}$ are certainly also affected by the overall poor performance of the system.

\section{Action spectra}

The action spectra of POP-B zippers Au-1-(2-3- $)_{n}$ confirmed that the blue NDI generates essentially no photocurrent (Fig. 6, $\bigcirc$ ). The same was true for OPE-B zippers Au-4-(5-6-) $)_{n}$ when excited around $600 \mathrm{~nm}$ (Fig. 6, -). However, the OPE chromophores in OPE-B zippers Au-4-(5-6-) $)_{n}$ were capable of generating significant photocurrent when excited around $400 \mathrm{~nm}$ (Fig. 6, ๑).

The finding that OPEs but not NDIs generate photocurrent in OPE-B zippers Au-4-(5-6-) ${ }_{n}$ was very interesting. Transient absorption spectroscopy has revealed that the SHJ-compatible $\mathrm{OPE}^{+}-\mathrm{NDI}^{-}$pair is accessible only by OPE excitation, whereas NDI excitation gives the SHJ-incompatible $\mathrm{NDI}^{+}{ }^{-} \mathrm{NDI}^{-}$pair. ${ }^{53}$ The perfect correlation of excitation wavelength-controlled activation of CS pathways with photocurrent generation suggested that the blue NDIs are incapable of generating photocurrent because excitation cannot be followed by hole transfer from the NDI stack to the OPE rod (Fig. 6, blue arrows). ${ }^{55,16}$ This observation implied that the electron but not the hole mobility in NDI stacks is sufficient to generate photocurrent, and that rod-stack SHJ systems are needed for significant function (Fig. 1).

Photocurrent generation by OPEs, however, was in agreement with ultrafast electron injection into the NDI in response to OPE excitation (Fig. 6, red arrows). ${ }^{55,2}$ The resulting rod-stack charge separation can initiate electron and hole transfer along the NDI stack and the string of OPE rods, respectively. Photocurrent generation by OPEs but not NDIs is thus in excellent support of

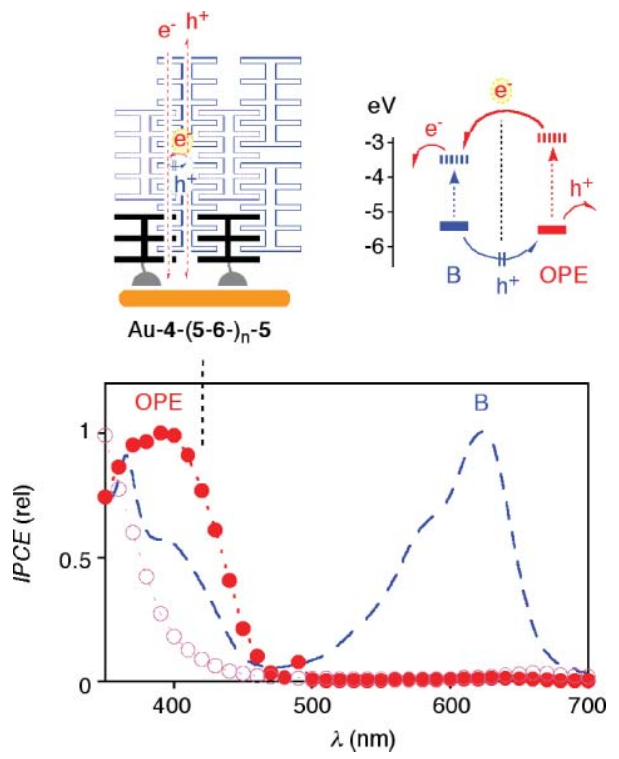

Fig. 6 Action spectra of POP-B zipper Au-1-(2-3- $)_{n}(\bigcirc)$ and OPE-B zipper Au-4-(5-6-) $)_{n}(-)$ with comparison to the absorption spectrum of OPE-B $\mathbf{5}$ and energy diagram for photocurrent generation by OPEs. IPCE $=$ incident photon-to-current efficiency, normalized to 1 at high energy.

the importance of the concept of SHJ photosystems. The bottom line is that the OPE-B zippers Au-4-(5-6-) $)_{n}$ are SHJ photosystems that operate only in response to the excitation of OPEs, and not of blue NDIs.

\section{Conclusions}

The key question of this study was whether or not OPE scaffolds could integrate blue NDIs into OMARG-SHJ photosystems. ${ }^{1}$ The short answer to this question is no. Blue NDIs in OPE-B architectures generate as little photocurrent as in POP-B architectures because the raised HOMO of OPE is still not high enough to engage in hole transfer after NDI excitation. However, excitation of OPE/POP rods was followed by electron transfer to NDIs to form formal SHJ photosystems. This finding was in agreement with the wavelength-dependent activation of different CS pathways observed in photophysical studies of the OPE architecture ${ }^{55}$ Clearly, higher photocurrents generated by OPE-B zippers compared to POP-B zippers could be rationalized by their better organization and the OPE absorption at wavelength where solar irradiance is highest. Other attractive characteristics 
identified for OPE-B systems include possible control of OPE planarity by sidechain interactions, compatibility with zipper architectures and responsiveness to topologically matching. To ultimately integrate blue NDIs into OMARG-SHJ photosystems, ${ }^{1}$ HOMO energies above those of the current OPEs will be needed. Synthetic efforts to tackle this challenge are currently ongoing.

\section{Acknowledgements}

We thank A. Perez-Velasco and D.-H. Tran for contributions to synthesis, D. Jeannerat, A. Pinto and S. Grass for NMR measurements, P. Perrottet N. Oudry and G. Hopfgartner for MS measurements, and the University of Geneva and the Swiss NSF and for financial support.

\section{References}

1 R. Bhosale, J. Misek, N. Sakai and S. Matile, Chem. Soc. Rev., 2010, 39, 138-149.

2 R. Bhosale, A. Perez-Velasco, V. Ravikumar, R. S. K. Kishore, O. Kel, A. Gomez-Casado, P. Jonkheijm, J. Huskens, P. Maroni, M. Borkovec, T. Sawada, E. Vauthey, N. Sakai and S. Matile, Angew. Chem., Int. Ed., 2009, 48, 6461-6464.

3 R. S. K. Kishore, O. Kel, N. Banerji, D. Emery, G. Bollot, J. Mareda, A. Gomez-Casado, P. Jonkheijm, J. Huskens, P. Maroni, M. Borkovec, E. Vauthey, N. Sakai and S. Matile, J. Am. Chem. Soc., 2009, 131, 11106-11116.

4 C. W. Tang, Appl. Phys. Lett., 1986, 48, 183-185.

5 G. Yu, J. Gao, J. C. Hummelen, F. Wudl and A. J. Heeger, Science, 1995, 270, 1789-1791.

6 B. C. Thompson and J. M. J. Fréchet, Angew. Chem., Int. Ed., 2008, 47, $58-77$.

7 S. Günes, H. Neugebauer and N. S. Sariciftci, Chem. Rev., 2007, 107, 1324-1338.

8 C. Ma, M. Fonrodona, M. C. Schikora, M. M. Wienk, R. A. J. Janssen and P. Bäuerle, Adv. Funct. Mater., 2008, 18, 3323-3331.

9 J.-F. Eckert, J.-F. Nicoud, J.-F. Nierengarten, S.-G. Liu, L. Echegoyen, N. Armaroli, F. Barigelletti, L. Ouali, V. Krasnikov and G. Hadziioannou, J. Am. Chem. Soc., 2000, 122, 7467-7479.

10 V. Balzani, M. Venturi and A. Credi, Molecular Devices and Machines, Wiley-VCH, Weinheim, 2003.

11 F. Yang, M. Shtein and S. Forrest, Nat. Mater., 2005, 4, 37-41.

12 S. Sista, Y. Yao, Y. Yang, M. L. Tang and Z. Bao, Appl. Phys. Lett., 2007, 91, 223508/1-223508/3.

13 I. Riedel, E. von Hauff, J. Parisi, N. Martín, F. Giacalone and V. Dyakonov, Adv. Funct. Mater., 2005, 15, 1979-1987.

14 N. Martín, L. Sánchez, M. Ángeles Herranz, B. Illescas and D. M. Guldi, Acc. Chem. Res., 2007, 40, 1015-1024.

15 N. Sakai, A. L. Sisson, T. Bürgi and S. Matile, J. Am. Chem. Soc., 2007, 129, 15758-15759.

16 A. L. Sisson, N. Sakai, N. Banerji, A. Fürstenberg, E. Vauthey and S. Matile, Angew. Chem., Int. Ed., 2008, 47, 3727-3729.

17 N. Sakai, R. S. K. Kishore and S. Matile, Org. Biomol. Chem., 2008, 6, 3970-3976.

18 M. Lista, N. Sakai and S. Matile, Supramol. Chem., 2009, 21, 238-244.

19 A. Kira, T. Umeyama, Y. Matano, K. Yoshida, S. Isoda, J. K. Park, D. Kim and H. Imahori, J. Am. Chem. Soc., 2009, 131, 3198-3200.

20 A. B. F. Martinson, A. M. Massari, S. J. Lee, R. W. Gurney, K. E. Splan, J. T. Hupp and S. T. Nguyen, J. Electrochem. Soc., 2006, 153, A527-A532.

21 D. M. Guldi, J. Phys. Chem. B, 2005, 109, 11432-11441.

22 D. M. Guldi, I. Zilbermann, G. Anderson, A. Li, D. Balbinot, N. Jux, M. Hatzimarinaki, A. Hirsch and M. Prato, Chem. Commun., 2004, 726-727.
23 F. B. Abdelrazzaq, R. C. Kwong and M. E. Thompson, J. Am. Chem. Soc., 2002, 124, 4796-4803.

24 H. J. Snaith, G. L. Whiting, B. Sun, N. C. Greenham, W. T. S. Huck and R. H. Friend, Nano Lett., 2005, 5, 1653-1657.

25 R. C. Shallcross, G. D. D'Ambruoso, B. D. Korth, H. K. Hall, Z. Zheng, J. Pyun and N. R. Armstrong, J. Am. Chem. Soc., 2007, 129, $11310-11311$.

26 E. Hwang, K. M. N. de Silva, C. B. Seevers, J.-R. Li, J. C. Garno and E. E. Nesterov, Langmuir, 2008, 24, 9700-9706.

27 C.-H. Huang, N. D. McClenaghan, A. Kuhn, G. Bravic and D. M. Bassani, Tetrahedron, 2006, 62, 2050-2059.

28 M. Morisue, S. Yamatsu, N. Haruta and Y. Kobuke, Chem.-Eur. J., 2005, 11, 5563-5574.

29 T. Van der Boom, R. T. Hayes, Y. Zhao, P. J. Bushard, E. A. Weiss and M. R. Wasielewski, J. Am. Chem. Soc., 2002, 124, 9582-9590.

30 F. Würthner, Z. Chen, F. J. M. Hoeben, P. Osswald, C.-C. You, P. Jonkheijm, J. Herrikhuyzen, A. P. H. J. Schenning, P. P. A. M. van der Schoot, E. W. Meijer, E. H. A. Beckers, S. C. J. Meskers and R. A. J. Janssen, J. Am. Chem. Soc., 2004, 126, 10611-10618.

31 Y. Yamamoto, T. Fukushima, Y. Suna, N. Ishii, A. Saeki, S. Seki, S. Tagawa, M. Taniguchi, T. Kawai and T. Aida, Science, 2006, 314, 17611764.

32 S. V. Bhosale, C. H. Jani and S. J. Langford, Chem. Soc. Rev., 2008, 37, 331-342.

33 C. Röger and F. Würthner, J. Org. Chem., 2007, 72, 8070-8075.

34 A. Blaszczyk, M. Fischer, C. von Hänisch and M. Mayor, Helv. Chim. Acta, 2006, 89, 1986-2005.

35 S. Chopin, F. Chaignon, E. Blart and F. Odobel, J. Mater. Chem., 2007, 17, 4139-4146.

36 S. Bhosale, A. L. Sisson, P. Talukdar, A. Fürstenberg, N. Banerji, E. Vauthey, G. Bollot, J. Mareda, C. Röger, F. Würthner, N. Sakai and S. Matile, Science, 2006, 313, 84-86.

37 N. Banerji, A. Fürstenberg, S. Bhosale, A. L. Sisson, N. Sakai, S. Matile and E. Vauthey, J. Phys. Chem. B, 2008, 112, 8912-8922.

38 F. Würthner, Chem. Commun., 2004, 1564-1579.

39 Y. Rio, M. S. Rodriguez-Morgade and T. Torres, Org. Biomol. Chem., 2008, 6, 1877-1894.

40 K. Tahara, T. Fujita, M. Sonoda, M. Shiro and Y. Tobe, J. Am. Chem. Soc., 2008, 130, 14339-14345.

41 M. Lopalco, E. N. Koini, J. K. Cho and M. Bradley, Org. Biomol. Chem., 2009, 7, 856-859.

42 O. Sadovski, A. A. Beharry, F. Zhang and G. A. Woolley, Angew. Chem., Int. Ed., 2009, 48, 1484-1486.

43 R. P. Haugland, The Handbook. A Guide to Fluorescent Probes and Labeling Techniques, 10th Edition, Invitrogen, 2005.

44 R. Koeppe, O. Bossart, G. Calzaferri and N. S. Sariciftci, Sol. Energy Mater. Sol. Cells, 2007, 91, 986-995.

45 R. A. Miller, A. D. Presley and M. B. Francis, J. Am. Chem. Soc., 2007, 129, 3104-3109.

46 B. A. Jones, A. Facchetti, M. R. Wasielewski and T. J. Marks, J. Am. Chem. Soc., 2007, 129, 15259-15278.

47 H. Yan, Z. Chen, Y. Zheng, C. Newman, J. R. Quinn, F. Dötz, M. Kastler and A. Facchetti, Nature, 2009, 457, 679-686.

48 J. Mareda and S. Matile, Chem.-Eur. J., 2009, 15, 28-37.

49 W. Hu, N. Zhu, W. Tang and D. Zhao, Org. Lett., 2008, 10, 2669-2672.

50 J. Kim and T. M. Swager, Nature, 2001, 411, 1030-1034.

51 M. K. Kuimova, M. Balaz, H. L. Anderson and P. R. Ogilby, J. Am. Chem. Soc., 2009, 131, 7948-7949.

52 S. B. Sachs, S. P. Dudek, R. P. Hsung, L. R. Sita, J. F. Smalley, M. D. Newton, S. W. Feldberg and C. E. D. Chidsey, J. Am. Chem. Soc., 1997, 119, 10563-10564.

53 B. Albinsson, M. P. Eng, K. Pettersson and M. U. Winters, Phys. Chem. Chem. Phys., 2007, 9, 5847-5864.

54 R. Huber, T. M. Gonzlez, S. Wu, M. Langer, S. Grunder, V. Horhoiu, M. Mayor, M. R. Bryce, C. Wang, R. Jitchati, C. Schoenenberger and M. Calame, J. Am. Chem. Soc., 2008, 130, 1080-1084.

55 N. Banerji, G. Duvanel, A. Perez-Velasco, S. Maity, N. Sakai, S. Matile and E. Vauthey, J. Phys. Chem. A, 2009, 113, 8202-8212. 